\title{
Hyperglycaemia-induced superoxide production decreases eNOS expression via AP-1 activation in aortic endothelial cells
}

\author{
S. Srinivasan ${ }^{1}$ M. E. Hatley ${ }^{1}$ D. T. Bolick ${ }^{1}$ L. A. Palmer ${ }^{2}$ D. Edelstein ${ }^{3}$ M. Brownlee B C. C. Hedrick $^{1}$ \\ ${ }^{1}$ Division of Endocrinology and Metabolism and the Cardiovascular Research Center, University of Virginia, Charlottesville, USA \\ 2 Department of Pediatrics and Anesthesiology, University of Virginia, Charlottesville, Virginia, USA \\ ${ }^{3}$ Diabetes Research Center, Albert Einstein College of Medicine, Bronx, New York, USA
}

\begin{abstract}
Aims/hypothesis. Hyperglycaemia is a primary cause of vascular complications in diabetes. A hallmark of these vascular complications is endothelial cell dysfunction, which is partly due to the reduced production of nitric oxide. The aim of this study was to investigate the regulation of endothelial nitric oxide synthase (eNOS) activity by acute and chronic elevated glucose. Methods. Human aortic endothelial cells were cultured in $5.5 \mathrm{mmol} / \mathrm{l}(\mathrm{NG})$ or $25 \mathrm{mmol} / \mathrm{l}$ glucose $(\mathrm{HG})$ for $4 \mathrm{~h}$, 1 day, 3 days or 7 days. Mouse aortic endothelial cells were freshly isolated from C57BL/6J control and diabetic $\mathrm{db} / \mathrm{db}$ mice. The expression and activity of eNOS were measured using quantitative PCR and nitrite measurements respectively. The binding of activator protein-1 (AP-1) to DNA in nuclear extracts was determined using electrophoretic mobility-shift assays.

Results. Acute exposure ( $4 \mathrm{~h})$ of human aortic endothelial cells to $25 \mathrm{mmol} / \mathrm{l}$ glucose moderately increased eNOS activity and eNOS mRNA and protein expression. In contrast, chronic exposure to elevated glucose
\end{abstract}

( $25 \mathrm{mmol} / \mathrm{l}$ for 7 days) reduced total nitrite levels $(46 \%$ reduction), levels of eNOS mRNA (46\% reduction) and eNOS protein (65\% reduction). In addition, AP-1 DNA binding activity was increased in chronic HGcultured human aortic endothelial cells, and this effect was reduced by the specific inhibition of reactive oxygen species production through the mitochondrial electron transport chain. Mutation of AP-1 sites in the human eNOS promoter reversed the effects of HG. Compared with C57BL/6J control mice, eNOS mRNA levels in diabetic $\mathrm{db} / \mathrm{db}$ mouse aortic endothelial cells were reduced by $60 \%$. This decrease was reversed by the overexpression of manganese superoxide dismutase using an adenoviral construct.

Conclusions/interpretation. In diabetes, the expression and activity of eNOS is regulated through glucosemediated mitochondrial production of reactive oxygen species and activation of the oxidative stress transcription factor AP-1.

Keywords AP-1 - Diabetes $\cdot$ Endothelial $\cdot$ eNOS · Superoxide
Received: 30 January 2004 / Accepted: 1 June 2004

Published online: 13 October 2004

C) Springer-Verlag 2004

C. C. Hedrick (

Division of Endocrinology and Metabolism

and the Cardiovascular Research Center,

University of Virginia, 415 Lane Rd, MR5, Rm G123,

P.O. Box 801394, Charlottesville, VA 22908, USA

E-mail: cch6n@virginia.edu

Tel.: +1-434-9824065, Fax: +1-434-9242828

Abbreviations: AP-1, activator protein-1 $\cdot$ EC, endothelial cell $\cdot$ eNOS, endothelial nitric oxide synthase $\cdot$ FBS, fetal bovine serum $\cdot \mathrm{HG}$, high glucose $\cdot$ MnSOD, manganese superoxide dismutase - MOI, multiplicity of infection . $\mathrm{NF}-\kappa \mathrm{B}$, nuclear factor- $\kappa \mathrm{B} \cdot \mathrm{NG}$, normal glucose $\cdot$ ROS, reactive oxygen species $\cdot$ UCP-1, uncoupling protein-1

\section{Introduction}

Hyperglycaemia is a primary cause of diabetic vascular complications. A hallmark of these vascular complications is endothelial cell (EC) dysfunction that is characterised by reduced nitric oxide-dependent phenomena, including vasodilation and protection against leucocyte-endothelial interactions. Studies have shown that hyperglycaemia impairs nitric oxide production $[1,2]$. Several studies have demonstrated impaired endothelium-dependent vasorelaxation in diabetic humans [3, 4] and in experimental diabetic animals [5, 6]. Hyperglycaemia alters the intracellular reductionoxidation (redox) state of the cell in several ways: (i) by increasing pro-oxidant enzyme activity, thus increasing superoxide generation; (ii) forming AGE that 
can propagate free-radical production; and (iii) by forming mitochondrial-derived reactive oxygen species (ROS). Several transcription factors, including nuclear factor- $\mathrm{\kappa B}(\mathrm{NF}-\kappa \mathrm{B})$, activator protein-1 (AP-1) and $\mathrm{c}$-jun are regulated by the redox state of the cell [7]. Several studies have indicated that mitochondrial function is involved in superoxide production [8,9]. Inhibition of mitochondrial function in human ECs blocks superoxide formation by the cell [8]. We have previously shown that ROS production is increased by chronic elevated glucose in human aortic ECs [10]. Furthermore, inhibition or uncoupling of the mitochondrial electron transport chain in ECs prevents the glucose-mediated increase in ROS $[9,10]$. We hypothesised that the overproduction of superoxide and other ROS in vascular cells by hyperglycaemia $[11,12,13$, 14] could modulate the activity of endothelial nitric oxide synthase (eNOS).

The activity of eNOS is regulated by both transcriptional and translational mechanisms. We have recently reported that mitochondrial ROS production in ECs can lead to the decreased phosphorylation of Ser1177 of eNOS [15]. In the present study, we examined additional mechanisms by which both acute and chronic elevated glucose regulate eNOS expression and activity in human aortic ECs.

\section{Materials and methods}

Reagents. Cell culture reagents were from Invitrogen (Carlsbad, Calif., USA). Fetal bovine serum (FBS) was from Hyclone (Logan, Utah, USA). CellLytic Nuclear extraction kit, protease inhibitor cocktail and anti-tubulin antibody were purchased from Sigma (St Louis, Mo., USA). Anti-eNOS antibody was obtained from BD Biosciences (San Diego, Calif., USA). Lipofectin, Trizol reagent and Thermoscript reverse transcriptase were also obtained from Invitrogen. The $\beta$-galactosidase assay and luciferase assay kits were purchased from Promega (Madison, Wis., USA). Nitrite assay kit was purchased from R\&D Systems (Minneapolis, Minn., USA). Human microvascular ECs used for transfections were a kind gift from J. Berliner (UCLA, Los Angeles, Calif., USA) and were originally obtained from clones at the Center for Disease Control (Atlanta, Ga., USA).

Mice. Young 12-week-old male db/db (Bb.Cg- $m^{+} /+$Lepr $\left.^{d b}\right)$ mice (stock no. 000697) were obtained from Jackson Laboratories (Bar Harbor, Me., USA). The $\mathrm{db} / \mathrm{db}$ mice (designated $\mathrm{db} / \mathrm{db}$ ) were on a pure C57BL6/J background strain. The control mice, 12-week-old male C57BL6/J mice (designated B6), were also from Jackson Laboratories (stock no. 000664). Mice were fed rodent chow and housed in micro-isolator cages in a pathogen-free facility. All experiments followed guidelines from the Association for Assessment of Laboratory Animal Care (AALAC) guidelines, and approval for use of rodents was obtained from the University of Virginia.

Endothelial cell culture. Human aortic ECs were obtained from aortic rings of explanted donor hearts [16] following approved guidelines from the University of Virginia Institutional Review Board and were maintained in culture as described [10]. Human aortic ECs were cultured in either $5.5 \mathrm{mmol} / \mathrm{l} \mathrm{D}$-glucose (NG),
$25 \mathrm{mmol} / \mathrm{l}$ D-glucose (HG) or $5.5 \mathrm{mmol} / \mathrm{l}$ D-glucose with $19.5 \mathrm{mmol} / \mathrm{l}$ mannitol (as an osmotic control) for the times indicated. Cells from passage 3 to 5 were used for experiments. For transfection experiments, human microvascular ECs were cultured in MCDB-131 supplemented with $15 \%$ heat-inactivated FBS, $10 \mathrm{ng} / \mathrm{ml}$ epidermal growth factor and $1 \mu \mathrm{g} / \mathrm{ml}$ hydrocortisone. Mouse aortic ECs were isolated from 16-week-old diabetic $\mathrm{db} / \mathrm{db}$ and control mice as described by our group previously [17]. Mouse ECs were cultured in DMEM containing $15 \%$ heat-inactivated FBS, $60 \mu \mathrm{g} / \mathrm{ml}$ endothelial cell growth supplement and $100 \mu \mathrm{g} / \mathrm{ml}$ heparin. For the purposes of this study, $\mathrm{C} 57 \mathrm{BL} / 6 \mathrm{~J}$ and $\mathrm{db} / \mathrm{db}$ ECs were maintained under normal glucose $(5.5 \mathrm{mmol} / \mathrm{l})$ conditions and used only at passage 2 . Both cell types were used at identical passage numbers and were cultured for identical lengths of time. All measurements were normalised to either total cell protein or to a housekeeping protein or gene as indicated to control for possible differences in cell growth related to diabetes. We have previously reported the use of diabetic $\mathrm{db} / \mathrm{db}$ ECs in related studies [17].

Measurement of $\mathrm{NOx}\left(\mathrm{NO}_{2}^{-}\right.$and $\left.\mathrm{NO}_{3}^{-}\right)$production by endothelial cells. Human aortic ECs were cultured under NG and HG conditions as described above. After the glucose treatment, the medium was changed to Hanks' balanced salt solution supplemented with L-arginine $(100 \mu \mathrm{mol} / \mathrm{l})$ and $\mathrm{CaCl}_{2}$ (1.3 mmol/l). After equilibrating for $30 \mathrm{~min}$ at $37{ }^{\circ} \mathrm{C}$, the $\mathrm{ECs}$ were stimulated by the addition of $5 \mu \mathrm{mol} / \mathrm{l}$ A23187 for $30 \mathrm{~min}$. The media were collected and the total nitrites in the media were quantitated by the Griess reaction. Results are expressed as nmol nitrite.mg protein ${ }^{-1} \cdot \mathrm{h}^{-1}$.

Immunoblotting of eNOS protein. Monolayers of ECs were rinsed with ice-cold PBS and were lysed using $20 \mathrm{mmol} / \mathrm{l}$ Tris$\mathrm{HCl} \mathrm{pH} 7.4,100 \mathrm{mmol} / \mathrm{l} \mathrm{NaCl}, 1 \%$ Igepal CA-630, 0.5\% sodium deoxycholate, $0.1 \%$ SDS, $100 \mu \mathrm{mol} / 1$ sodium orthovanadate and protease inhibitor cocktail. Samples were sonicated for $20 \mathrm{~s}$ and then centrifuged for $10 \mathrm{~min}$ at $13,000 \mathrm{rev} / \mathrm{min}$. The supernatant was removed and protein was measured using a protein assay kit (BioRad, Hercules, Calif., USA). Total protein $(10 \mu \mathrm{g})$ in SDS sample buffer was heated to $95^{\circ} \mathrm{C}$ and the proteins were separated by SDS-PAGE using a denaturing 4-12\% gel. Proteins were transferred to nitrocellulose and then blocked for $2 \mathrm{~h}$ with Blocker-Casein (Pierce, Rockford, Ill., USA). Nitrocellulose blots were incubated with antibodies to eNOS (1:1000) and tubulin (1:5000) overnight at $4{ }^{\circ} \mathrm{C}$. Bands were visualised using the appropriate horseradish peroxidaselinked secondary antibodies and chemiluminescence.

Electrophoretic-mobility-shift assay for AP-1. Human aortic ECs were cultured in NG and $\mathrm{HG}$ as described above. Cells were transfected for $48 \mathrm{~h}$ at $37{ }^{\circ} \mathrm{C}$ with recombinant adenoviruses expressing rat uncoupling protein-1 (UCP-1), human manganese superoxide dismutase (MnSOD) or $\beta$-galactosidase using a multiplicity of infection (MOI) of 50. These adenoviruses have been described previously and have been shown to provide high levels of expression of the designated protein in primary endothelial cells [15]. After $48 \mathrm{~h}$ of incubation with adenovirus, cells were harvested by scraping with a cell scraper. Nuclear proteins were prepared using a CellLytic NuCLEAR extraction kit according to manufacturer's instructions (Sigma). Nuclear proteins were quantitated using a BioRad DC protein assay kit.

Electrophoretic-mobility-shift assays for AP-1 were performed as described previously $[10,18]$ using $5 \mu \mathrm{g}$ of nuclear extract. The sequence of the sense strand of the double-stranded AP-1 oligonucleotide probe was 5'-CGCTTGATGAGTCAGCCGGAA-3'. A molar excess of cold AP-1 was added as a control. 
Quantitative PCR for human and murine eNOS. Total cellular RNA was isolated using Trizol reagent following the manufacturer's protocol. The cDNA was synthesised using Thermoscript reverse transcriptase [10]. Quantitative PCR was performed for eNOS and $\beta$-actin in a BioRad iCycler PCR instrument equipped with a real-time camera detection module. The primer sequences and the PCR conditions for human eNOS were as described by Gan et al. [19]. The sequences of the murine eNOS primers used were: forward: 5'-TAC GCA CCC AGA GCT TTT CT-3' and reverse: 5'-CTT GGT CAA CCG AAC GAA GT-3'. Data were analysed and presented based upon the relative expression method [20] using the following equation:

Relative expression $=2^{-(S \Delta C T-C \Delta C T)}$

where $\Delta \mathrm{CT}$ is the difference in threshold cycle between the gene of interest (eNOS) and the housekeeping gene (cyclophilin). In this equation, $\mathrm{S}=\mathrm{HG}$ or $\mathrm{db} / \mathrm{db}$ mice and $\mathrm{C}=\mathrm{NG}$ or B6 control mice.

eNOS promoter studies. Human microvascular ECs were utilised in transfection experiments due to their high efficiency of transfection (80-90\%). Primary human aortic ECs do not transfect with high efficiency using conventional approaches. Human microvascular ECs were cultured as described above and were transiently transfected using Lipofectin with either a plasmid containing bases -1600 to +22 of the human eNOS promoter fused to a luciferase reporter construct (plasmid F1) or transfected with a plasmid containing bases -1600 to +22 of the human eNOS promoter with two mutated AP-1 sites (plasmid AP-1 Mut) [21]. The AP-1 site was mutated using the Quickchange site-directed mutagenesis kit (Stratagene, La Jolla, Calif., USA) using oligonucleotides with the following sequences: 5'-GCT CCA TTA ACT GGG ACC TAG GAA AAT CTC GAG TCC TTG GTC ATG C-3' and 3'-CGA GGT AAT TGA CCC TGG ATC CTT TTA GAG CTC AGG AAC CAG TAC G-5'. Cells were co-transfected with a $\beta$-galactosidase vector for normalisation purposes. Lipofectin was used according to the manufacturer's protocol. After transfection, the cells were cultured in media containing NG or $\mathrm{HG}$ for $48 \mathrm{~h}$ prior to harvest. Cells were lysed using reporter lysis buffer (Promega), and luciferase activity was assayed by measuring luminescence. The activity of $\beta$-galactosidase was measured using a kit according to manufacturer's instructions. Luciferase activity values were normalised to $\beta$-gal expression.

Statistical analysis. Comparisons between groups were performed using ANOVA. Data are presented as means \pm SEM of five experiments performed in quadruplicate (unless otherwise noted in the Figure Legends). Mouse analyses were performed using six mice per group. All comparisons were made using Fisher's least significant difference procedure, so that multiple comparisons were made at the 0.05 level only if the overall F-test from the ANOVA was significant, indicated by a $p$ value of less than 0.05 .

\section{Results}

Chronic elevated glucose reduces nitric oxide production in endothelial cells. Human aortic ECs were cultured in the presence of $5.5 \mathrm{mmol} / \mathrm{l} \mathrm{D}$-glucose $(\mathrm{NG})$, $25 \mathrm{mmol} / \mathrm{l} \mathrm{D}$-glucose (HG) or $5.5 \mathrm{mmol} / \mathrm{l} \mathrm{D}$-glucose with $19.5 \mathrm{mmol} / \mathrm{l}$ mannitol for $4 \mathrm{~h}, 1$ day, 3 days or 7 days. Human aortic ECs were viable for 7 days in

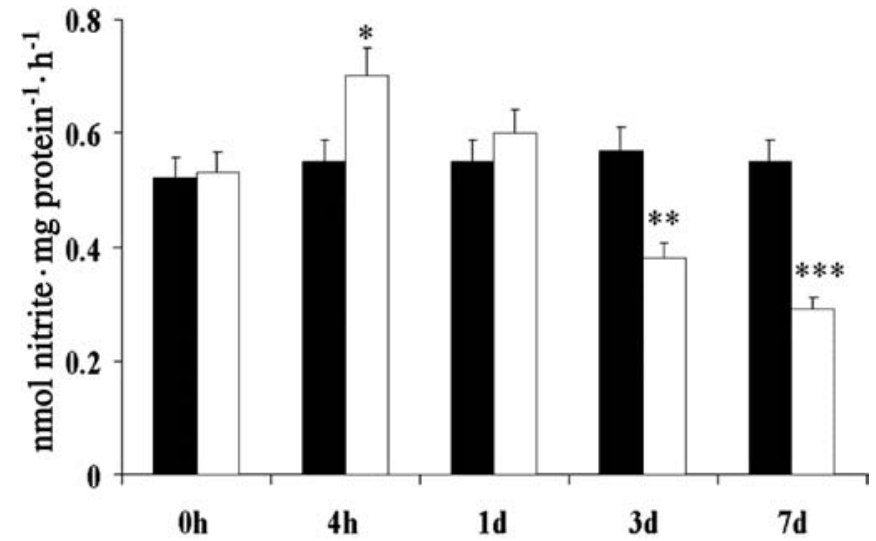

Fig. 1. Glucose reduces endothelial nitrite production. Human aortic ECs were cultured in media containing either $5.5 \mathrm{mmol} / \mathrm{l}$ glucose (NG, black bars) or $25 \mathrm{mmol} / \mathrm{l}$ glucose (HG, white bars) for $0 \mathrm{~h}$ (starting point of incubation), $4 \mathrm{~h}, 1$ day, 3 days or 7 days. Media were assayed for total nitrite formation as described in Materials and methods. The data shown are the means \pm SEM of four experiments. ${ }^{*} p<0.05$ vs NG; ${ }^{* *} p<0.005$ vs NG; ${ }^{* * *} p<0.001$ vs NG by ANOVA

$25 \mathrm{mmol} / \mathrm{l} \mathrm{D}$-glucose and in $5.5 \mathrm{mmol} / \mathrm{l} \mathrm{D}$-glucose with $19.5 \mathrm{mmol} / \mathrm{l}$ mannitol, and appeared healthy with normal morphology. After incubation for the designated times in glucose, samples of the media were collected and analysed for levels of total nitrite. Values were normalised to cell protein to account for any possible change in cell number due to glucose culture. There were no changes in total nitrite production in NGcultured cells at any of the time points analysed (Fig. 1). Acute glucose exposure (HG) for $4 \mathrm{~h}$ slightly increased (22\%) total cellular nitrite production $(p<0.05)$ (Fig. 1). In contrast, nitrite levels were significantly reduced by Day 3 and Day 7 of treatment $(30 \%$ and $46 \%$ respectively, $p<0.001)$. In human aortic ECs cultured in $5.5 \mathrm{mmol} / \mathrm{l} \mathrm{D}$-glucose with $19.5 \mathrm{mmol} / \mathrm{l}$ mannitol (osmotic control) nitrite production did not change significantly during the study (data not shown). Taken together, these results suggest an inverse relationship between the duration of $\mathrm{HG}$ exposure and the amount of total nitrite present in the media, indicating that glucose decreases eNOS activity.

Glucose reduces eNOS expression in aortic endothelial cells. To examine whether the decrease in nitric oxide production as measured by nitrite levels was a result of glucose-mediated changes in eNOS protein expression, immunoblotting was performed on lysates obtained from NG- and HG-cultured human aortic ECs. No changes in eNOS expression were observed in NG-cultured human aortic ECs during the course of the study (data not shown). Compared with NG-cultured human aortic ECs, expression of eNOS protein initially increased by $8 \%$ after $4 \mathrm{~h}$ exposure to $\mathrm{HG}$, then gradually declined by $65 \%$ over 7 days (Fig. 2). Thus, eNOS protein levels are decreased by chronic elevated glucose. 


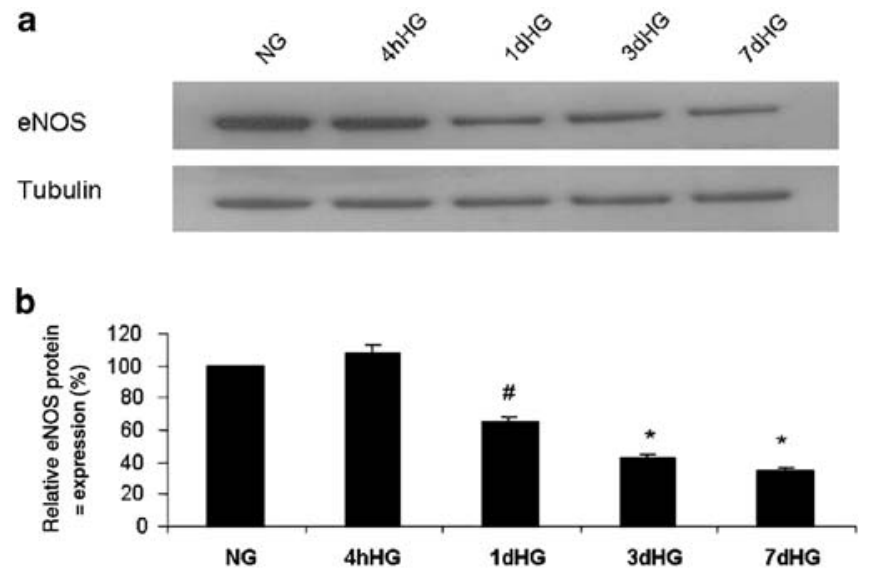

Fig. 2. Chronic elevated glucose down-regulates eNOS protein expression. EC lysates $(10 \mu \mathrm{g})$ were analysed by SDS-PAGE and transferred to nitrocellulose. The nitrocellulose membrane was probed with monoclonal antibodies to human eNOS and tubulin. a. A representative immunoblot of eNOS and tubulin protein expression in response to $5.5 \mathrm{mmol} / \mathrm{l}$ glucose $(\mathrm{NG})$ or $25 \mathrm{mmol} / 1$ glucose (HG) for $4 \mathrm{~h}$ (4hHG), 1 day ( $1 \mathrm{dHG}), 3$ days (3dHG) or 7 days $(7 \mathrm{dHG})$. b. Graph depicting the ratio of eNOS : tubulin protein expressed as a percentage of control glucose values (NG) as analysed by densitometry. NG is set at $100 \%$ for normalisation purposes. The data shown on the graph are the means \pm SEM of six experiments. ${ }^{*} p<0.01$ vs NG; ${ }^{*} p<0.001$ vs NG by ANOVA

Regulation of eNOS transcription by oxidative stress through AP-1. Quantitative real-time PCR was performed in human aortic ECs to determine whether the glucose-induced decrease in eNOS protein expression was a result of decreased levels of eNOS mRNA. In human aortic ECs cultured in HG for 3 and 7 days levels of eNOS mRNA were reduced by $25 \%$ and $46 \%$ respectively ( $p<0.01$ for both) (Fig. 3). Changes in eNOS mRNA levels paralleled the observed trend for protein levels (Fig. 2); eNOS mRNA levels did not change in the NG-cultured human aortic ECs over time (data not shown).

Previous analysis of the $-1600 \mathrm{bp}$ to $+21 \mathrm{bp}$ segment of the human eNOS promoter revealed the presence of two AP-1 binding sites, located at $-1530 \mathrm{bp}$ and -662 bp [21]. To test whether AP-1 activation by ROS leads to a reduction in eNOS mRNA levels, a series of transfections using human eNOS promoterreporter constructs were performed. Human microvascular ECs, which respond to elevated glucose in a manner similar to human aortic ECs (data not shown), were transfected with wild-type (F1) and AP-1-mutated (AP1 Mut) human eNOS promoter constructs. Human microvascular ECs were utilised in these experiments due to their high degree of transfection efficiency (80-90\%) using conventional approaches. Human microvascular ECs cultured for 7 days in $25 \mathrm{mmol} / \mathrm{l}$ glucose (HG) showed a $40 \%$ reduction in eNOS promoter activity compared with NG-cultured ECs, suggesting that glucose blocks eNOS promoter activation.

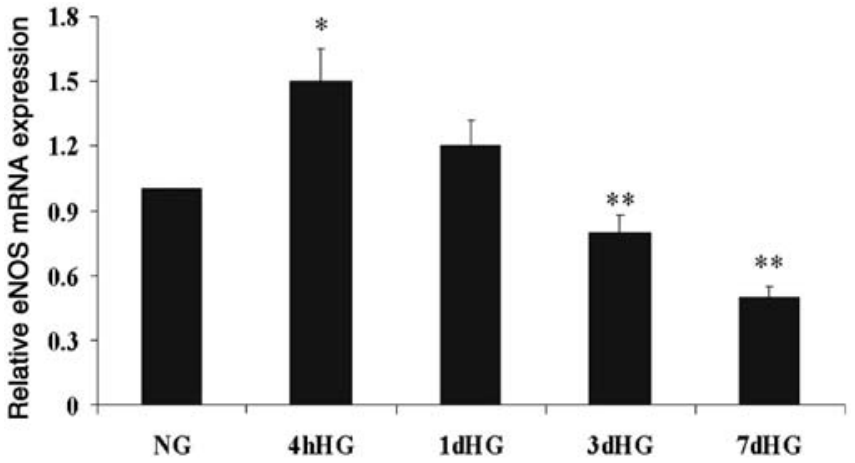

Fig. 3. Chronic elevated glucose down-regulates eNOS mRNA expression in human aortic ECs. Quantitative real-time PCR for eNOS and $\beta$-actin were performed as described in Materials and methods in human aortic ECs cultured in $5.5 \mathrm{mmol} / \mathrm{l}$ glucose (NG) or $25 \mathrm{mmol} / \mathrm{l}$ glucose $(\mathrm{HG})$ for $4 \mathrm{~h}(4 \mathrm{hHG}), 1$ day ( $1 \mathrm{dHG}), 3$ days $(3 \mathrm{dHG})$ or 7 days $(7 \mathrm{dHG})$. The relative expression of eNOS mRNA to $\beta$-actin mRNA is shown. The data shown are the means \pm SEM of five experiments. ${ }^{*} p<0.01$ vs NG; ${ }^{* *} \mathrm{p}<0.009$ vs NG by ANOVA

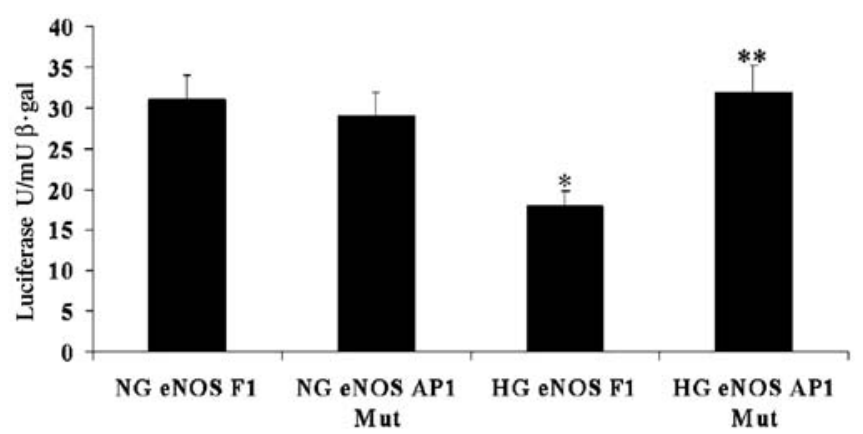

Fig. 4. Glucose modulates human eNOS promoter activity through the transcription factor AP-1. Human microvascular ECs were transfected with a plasmid containing -1600 to $+22 \mathrm{bp}$ of the human eNOS promoter linked to a luciferase reporter gene (eNOS F1) or -1600 to $+22 \mathrm{bp}$ of the human eNOS promoter containing mutated AP-1 sites (eNOS AP1 Mut). The data show the means \pm SEM of five transfection experiments. Chronic elevated glucose treatment $(25 \mathrm{mmol} / \mathrm{l}$ for 7 days) caused a significant reduction in human eNOS promoter activation (HG eNOS F1) as measured by luciferase activity. However, mutation of the AP-1 sites in the human eNOS promoter prevented the glucose-mediated decrease in promoter activity (HG eNOS AP1 Mut). * $p<0.01 \mathrm{vs} \mathrm{NG;}{ }^{* *} p<0.005$ vs HG eNOS F1 by ANOVA

Interestingly, mutating the AP-1 sites abolished the glucose-mediated inhibition of eNOS promoter activation (Fig. 4).

Elevated production of ROS has been reported in human aortic ECs cultured chronically in elevated glucose [10]. In addition, AP-1 activity is regulated by chronic elevated glucose [10]. To determine whether AP-1 binding activity is altered in the presence of glucose, electrophoretic-mobility-shift assays were performed. In these experiments, the binding of AP-1 to DNA was increased in human aortic ECs cultured in HG for 7 days compared with those cultured in NG 


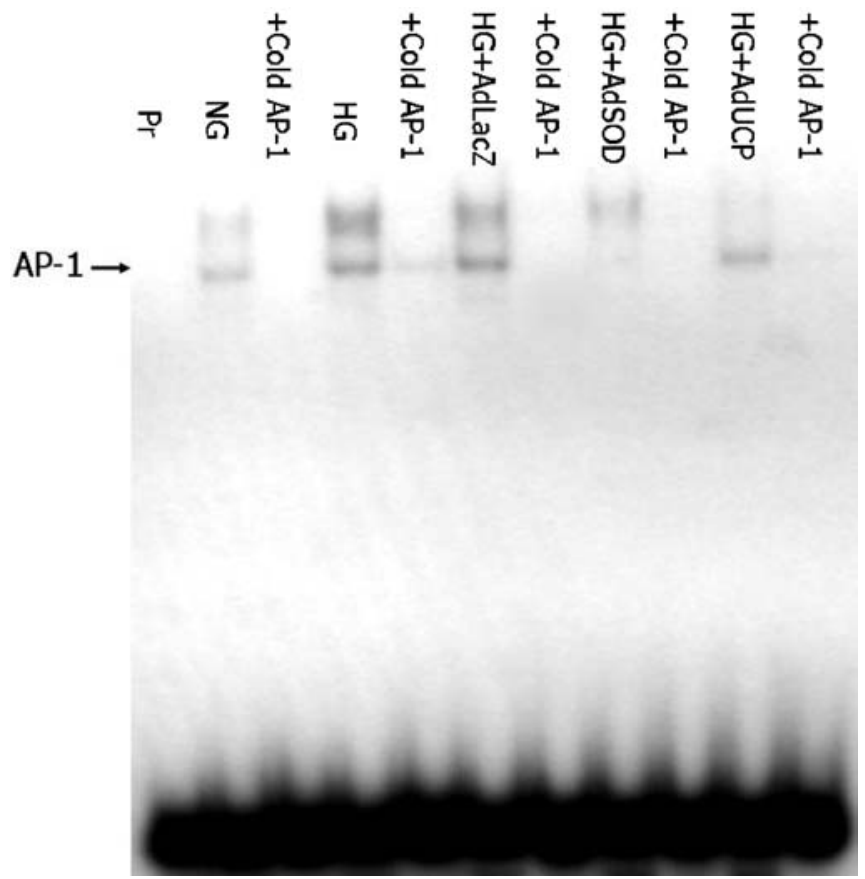

Fig. 5. Inhibition of mitochondrial ROS production in ECs reduces AP-1 binding to DNA. An electrophoretic-mobility-shift assay for AP-1 was performed using nuclear extracts from human aortic ECs cultured in $5.5 \mathrm{mmol} / \mathrm{l}$ glucose $(\mathrm{NG})$ or $25 \mathrm{mmol} / \mathrm{l}$ glucose (HG) for 7 days. On Day 5 of HG incubation, ECs were incubated with adenoviral vectors expressing either $\beta$-galactosidase (+AdLacZ) as a control, human MnSOD (+AdSOD) or rat UCP-1 (+AdUCP-1). Cold AP-1 was added as a control as described in Materials and methods. The arrow indicates the AP-1 band. Pr, Probe alone

(Fig. 5). Acute glucose exposure (less than 3 days) in HG had no effect on AP-1 binding activity (data not shown). Using electrophoretic-mobility-shift assays, we demonstrated a significant increase in AP-1 binding activity after 3 days of HG culture. In ECs cultured in HG for 7 days, inhibition of mitochondrial respiration using adenoviral overexpression of $\mathrm{Mn}$ SOD and UCP-1 significantly decreased AP-1 binding activity (Fig. 5), although MnSOD had a greater effect on AP-1 binding than UCP-1. Thus, regulation of AP-1 by ROS in chronic glucose conditions probably accounts for the observed decrease in eNOS mRNA levels. Taken together, our results strongly suggest that glucose-mediated production of ROS decreases eNOS expression in ECs through activation of the transcription factor AP-1.

Diabetic db/db mice have decreased eNOS mRNA expression in endothelial cells. In order to measure eNOS expression in diabetic $\mathrm{db} / \mathrm{db}$ mice in vivo we obtained freshly isolated aortic ECs from diabetic $\mathrm{db} / \mathrm{db}$ mice. Using real-time quantitative PCR, we found that, compared with control B6 ECs, eNOS mRNA levels were reduced by $60 \%$ in diabetic $\mathrm{db} / \mathrm{db}$ ECs (Fig. 6). This suggests that eNOS activity is regulated at the transcriptional level in diabetic mice in

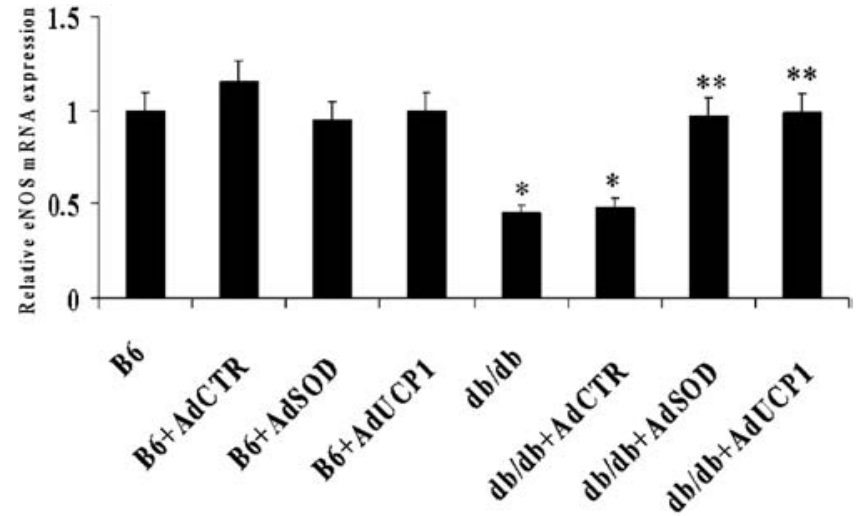

Fig. 6. Levels of eNOS mRNA are reduced in diabetic $\mathrm{db} / \mathrm{db}$ mice in vivo and are regulated by endothelial ROS production. Total RNA was isolated from B6 control (B6) and db/db diabetic $(\mathrm{db} / \mathrm{db})$ mouse aortic endothelium that had been incubated for $48 \mathrm{~h}$ in the presence of either an empty adenoviral vector (+AdCTR), and adenovirus expressing rat UCP-1 or an adenovirus expressing human MnSOD (+AdSOD). Quantitative realtime PCR for murine eNOS was performed and normalised to cyclophilin. The data shows mRNA expression relative to the B6 control value. * $p<0.001$ vs B6; ** $p<0.009$ vs db/db

vivo. Interestingly, inhibition of the mitochondrial electron transport chain using specific adenoviral constructs blocked the glucose-mediated decrease in eNOS mRNA observed in db/db mice (Fig. 6). Overexpression of either rat MnSOD or human UCP-1 completely reversed the decrease in eNOS mRNA found in diabetic $\mathrm{db} / \mathrm{db}$ mice. These data indicate that the decrease in eNOS expression in diabetic mice is due to increased endothelial mitochondrial ROS production. Scavenging of ROS by MnSOD and UCP-1 completely reversed the down-regulation of eNOS mRNA expression in diabetic mouse ECs.

\section{Discussion}

The influence of hyperglycaemia on the synthesis and release of nitric oxide by ECs has been the subject of intense interest over the last decade. Mechanisms underlying eNOS dysfunction in diabetes include: (i) decreased expression of eNOS; (ii) decreased phosphorylation of eNOS; (iii) increased degradation of nitric oxide, secondary to enhanced superoxide production in diabetes; and (iv) changes in expression of cofactors in the eNOS complex that are important for regulating eNOS activity [22, 23, 24]. The present study is the first to link chronic elevated glucose with modulation of EC eNOS mRNA levels through mitochondrial production of ROS with subsequent activation of AP-1. Our results show that glucose decreases eNOS mRNA and protein expression in human ECs through regulation of mitochondrial production of ROS. Mitochondrial ROS, in turn, activate the transcription factor AP-1 $[25,26]$ and cause increased AP-1 binding to DNA (Fig. 5). 
We observed changes in AP-1 binding activity in human aortic ECs in response to chronic but not acute elevated glucose exposure. Human aortic ECs cultured for less than 3 days in $25 \mathrm{mmol} / \mathrm{l}$ glucose $(\mathrm{HG})$ showed no change in AP-1 binding activity by electrophoretic-mobility-shift assay (data not shown). However, beginning at Day 3, there was a consistent and significant stepwise increase in AP-1 binding activity, with maximal AP-1 binding activity occurring at Day 7 of elevated glucose culture. The mechanism by which ROS stimulates AP-1 binding activity is unknown; however, AP-1 is clearly activated by cellular oxidative stress [27]. Thus, we hypothesise that EC cultured in elevated glucose generate superoxide production over time (through mitochondrial respiration) that results in the activation of oxidative stress-related signalling pathways, including activation of the transcription factor AP-1.

The regulation of AP-1 activation by inhibitors of mitochondrial respiration is an important and novel finding (Fig. 5). Overexpression of MnSOD and UCP-1 reduces AP-1 binding in HG-cultured ECs (Fig. 5). In the current study, using a series of human eNOS promoter-reporter constructs, we found that glucose significantly decreased eNOS promoter activation (Fig. 4). Interestingly, when the AP-1 binding sites on the human eNOS promoter were mutated, glucose was no longer able to down-regulate eNOS promoter activation and eNOS promoter activity was restored to levels observed for control ECs (Fig. 4). Thus, production of ROS by chronic elevated glucose, as occurs in diabetes, leads to the down-regulation of eNOS gene transcription through activation of AP-1. Inhibition of ROS production reduces AP-1 levels and prevents eNOS down-regulation. This is supported by the studies we performed in diabetic $\mathrm{db} / \mathrm{db}$ mice. The expression of eNOS mRNA was reduced in diabetic $\mathrm{db} / \mathrm{db}$ mice compared with that in control B6 mice. Furthermore, inhibition of mitochondrial production of ROS in $\mathrm{db} / \mathrm{db}$ mice reversed the down-regulation of eNOS mRNA expression. Together, these data suggest that mitochondrial ROS production by glucose mediates changes in endothelial eNOS expression in diabetes through AP-1. However, we cannot rule out the role of other pro-inflammatory signalling pathways, such as NF- $\kappa \mathrm{B}$, on the modulation of eNOS expression in ECs. Previous reports have shown that chronic elevated glucose stimulates NF- $\mathrm{KB}$ activation that can result in the down-regulation of eNOS [12]. We also cannot exclude the possibility that glucose directly modulates eNOS expression in ECs. We have not examined the direct effects of glucose or the impact of NF- $\kappa \mathrm{B}$ activation on eNOS expression in our model.

We have previously reported the increased production of superoxide in human and bovine ECs cultured chronically in elevated glucose $[9,10]$. ROS can be generated in endothelial cells through NADPH oxidase and/or mitochondrial respiration. Other reports have suggested that the diminished eNOS protein levels observed in ECs cultured chronically in elevated glucose were caused by increased cellular oxidative stress [28]. Under hypoxic conditions, eNOS transcription in porcine aortic ECs was reported to be regulated by NADPH oxidase [29]. However, we have reported that eNOS phosphorylation in bovine aortic ECs is regulated almost solely by mitochondrial respiration [15]. In diabetic $\mathrm{db} / \mathrm{db}$ mice, eNOS transcription is regulated almost entirely by mitochondrial respiration (Fig. 6). However, we did not examine the regulation of NADPH oxidase activity in diabetic mice in detail; consequently, we cannot rule out the possibility that NADPH oxidase contributes to this process.

The current study examined the effects of both acute and chronic elevated glucose on human eNOS expression. A primary mechanism for the regulation of eNOS activity is through modulation of eNOS protein expression. In human aortic ECs, eNOS mRNA and protein expression increase in response to acute elevated glucose; however, the expression of both decreases significantly over time (Figs. 2, 3). Several studies have reported the regulation of eNOS expression by glucose, though with conflicting results. Salt and co-workers reported that chronic elevated glucose reduced eNOS activity in the absence of changes in eNOS phosphorylation [30]. Ho and colleagues reported that eNOS protein expression in HUVECs was up-regulated by acute high glucose $(33 \mathrm{mmol} / \mathrm{l})$ exposure for 2 to $6 \mathrm{~h}$, and gradually decreased after longer exposure [31]. Conversely, Cosentino et al. have reported the up-regulation of eNOS expression after the exposure of human aortic ECs to $22 \mathrm{mmol} / \mathrm{l}$ glucose for 5 days [11]. In the present study we have examined a complete time course of glucose exposure and demonstrated that the acute response of the ECs to elevated glucose is to up-regulate eNOS activity; however, eNOS activation is gradually switched off in response to chronic elevated glucose.

Activation of eNOS is also regulated by the phosphorylation of Ser1177 of eNOS [32]. Phosphorylation enhances the electron flux through the protein domains of eNOS, resulting in increased nitric oxide production [33]. In human aortic ECs, Ser1177 of eNOS is phosphorylated by the serine/threonine kinase Akt $[34,35]$. In the present study, significant decreases in eNOS phosphorylation were observed 1 day after culture in $25 \mathrm{mmol} / \mathrm{l}$ glucose (data not shown). Regulation of eNOS phosphorylation by ROS, such as peroxynitrite, has previously been observed [36]. We have recently reported the regulation of eNOS phosphorylation by mitochondrial ROS production and hyperglycaemia in ECs [15].

Nitric oxide has also been shown to react with superoxide radicals to generate peroxynitrite which, in turn, rapidly oxidises the eNOS cofactor tetrahydrobiopterin to its inactive form, dihydrobiopterin [37]. 
This leads to uncoupling of eNOS [37, 38, 39]. Uncoupling of eNOS by ROS may be an additional mechanism by which glucose contributes to endothelial dysfunction [40]. Our current data suggest that the primary role of ROS in hyperglycaemia is the regulation of eNOS transcription rather than the uncoupling of eNOS.

In conclusion, prolonged exposure of human aortic ECs to elevated glucose induces cellular oxidative stress due to the overproduction of mitochondrial ROS. A primary mechanism for the down-regulation of activity and expression of eNOS is the modulation of eNOS mRNA transcription by the transcription factor AP-1. In human aortic ECs, AP-1 is activated by ROS. This, in turn, contributes to the down-regulation of eNOS protein levels and decreased phosphorylation and hence decreased activation of eNOS.

Acknowledgements. The authors would like to thank J. L. Nadler (University of Virginia) for helpful discussions and C. McNamara (University of Virginia) for the gift of the $\beta$-galactosidase expression plasmid. This work was supported by a grant from the National Institutes of Health (grant number P01 HL55798-08, C. C. Hedrick) and the American Heart Association (Mid-Atlantic Affiliate; C. C. Hedrick).

\section{References}

1. Ding Y, Vaziri ND, Coulson R, Kamanna VS, Roh DD (2000) Effects of simulated hyperglycaemia, insulin, and glucagon on endothelial nitric oxide synthase expression. Am J Physiol Endocrinol Metab 279:E11-E17

2. Guo X, Chen LW, Liu WL, Guo ZG (2000) High glucose inhibits expression of inducible and constitutive nitric oxide synthase in bovine aortic endothelial cells. Acta Pharmacol Sin 21:325-328

3. Steinberg HO, Chaker H, Leaming R, Johnson A, Brechtel G, Baron AD (1996) Obesity/insulin resistance is associated with endothelial dysfunction. Implications for the syndrome of insulin resistance. J Clin Invest 97:2601-2610

4. Makimattila S, Virkamaki A, Groop PH et al. (1996) Chronic hyperglycemia impairs endothelial function and insulin sensitivity via different mechanisms in insulindependent diabetes mellitus. Circulation 94:1276-1282

5. Dai FX, Diederich A, Skopec J, Diederich D (1993) Diabetes-induced endothelial dysfunction in streptozotocintreated rats: role of prostaglandin endoperoxides and free radicals. J Am Soc Nephrol 4:1327-1336

6. Pflueger AC, Osswald H, Knox FG (1999) Adenosineinduced renal vasoconstriction in diabetes mellitus rats: role of nitric oxide. Am J Physiol 276:F340-F346

7. Sen CK, Packer L (1996) Antioxidant and redox regulation of gene transcription. FASEB J 10:709-720

8. Mabile L, Meilhac O, Escargueil-Blanc I et al. (1997) Mitochondrial function is involved in LDL oxidation mediated by human cultured endothelial cells. Arterioscler Thromb Vasc Biol 17:1575-1582

9. Nishikawa T, Edelstein D, Du XL et al. (2000) Normalizing mitochondrial superoxide production blocks three pathways of hyperglycaemic damage. Nature 404:787-790

10. Srinivasan S, Yeh M, Danziger EC et al. (2003) Glucose regulates monocyte adhesion through endothelial production of interleukin-8. Circ Res 92:371-377
11. Cosentino F, Hishikawa K, Katusic ZS, Luscher TF (1997) High glucose increases nitric oxide synthase expression and superoxide anion generation in human aortic endothelial cells. Circulation 96:25-28

12. Du X, Stocklauser-Farber K, Rosen P (1999) Generation of reactive oxygen intermediates, activation of NF-kappaB, and induction of apoptosis in human endothelial cells by glucose: role of nitric oxide synthase? Free Radic Biol Med 27:752-763

13. Du XL, Edelstein D, Rossetti L et al. (2000) Hyperglycemia-induced mitochondrial superoxide overproduction activates the hexosamine pathway and induces plasminogen activator inhibitor-1 expression by increasing Sp1 glycosylation. Proc Natl Acad Sci USA 97:12222-12226

14. Baynes JW (1991) Role of oxidative stress in development of complications in diabetes. Diabetes 40:405-412

15. Du XL, Edelstein D, Dimmeler S, Ju Q, Sui C, Brownlee M (2001) Hyperglycaemia inhibits endothelial nitric oxide synthase activity by posttranslational modification at the Akt site. J Clin Invest 108:1341-1348

16. Patricia MK, Kim JA, Harper CM et al. (1999) Lipoxygenase products increase monocyte adhesion to human aortic endothelial cells. Arterioscler Thromb Vasc Biol 19:2615-2622

17. Hatley ME, Srinivasan S, Reilly KB, Bolick DT, Hedrick CC (2003) Increased production of 12/15 lipoxygenase eicosanoids accelerates monocyte/endothelial interactions in diabetic db/db mice. J Biol Chem 278:25369-25375

18. Yeh M, Leitinger N, Martin R de et al. (2001) Increased transcription of IL-8 in endothelial cells is differentially regulated by TNF-alpha and oxidized phospholipids. Arterioscler Thromb Vasc Biol 21:1585-1591

19. Gan LM, Selin-Sjogren L, Doroudi R, Jern S (2000) Temporal regulation of endothelial ET-1 and eNOS expression in intact human conduit vessels exposed to different intraluminal pressure levels at physiological shear stress. Cardiovasc Res 48:168-177

20. Livak KJ, Schmittgen TD (2001) Analysis of relative gene expression data using real-time quantitative PCR and the 2(-Delta Delta C(T)) method. Methods 25:402-408

21. Zhang R, Min W, Sessa WC (1995) Functional analysis of the human endothelial nitric oxide synthase promoter. Sp1 and GATA factors are necessary for basal transcription in endothelial cells. J Biol Chem 270:15320-15326

22. Sessa WC, Garcia-Cardena G, Liu J et al. (1995) The Golgi association of endothelial nitric oxide synthase is necessary for the efficient synthesis of nitric oxide. J Biol Chem 270:17641-17644

23. Liu J, Garcia-Cardena G, Sessa WC (1996) Palmitoylation of endothelial nitric oxide synthase is necessary for optimal stimulated release of nitric oxide: implications for caveolae localization. Biochemistry 35:13277-13281

24. Garcia-Cardena G, Fan R, Shah V et al. (1998) Dynamic activation of endothelial nitric oxide synthase by Hsp90. Nature 392:821-824

25. Ross R (1993) The pathogenesis of atherosclerosis: a perspective for the 1990s. Nature 362:801-809

26. Marui N, Offermann MK, Swerlick R et al. (1993) Vascular cell adhesion molecule-1 (VCAM-1) gene transcription and expression are regulated through an antioxidant-sensitive mechanism in human vascular endothelial cells. J Clin Invest 92:1866-1874

27. Lavrovsky Y, Chatterjee B, Clark RA, Roy AK (2000) Role of redox-regulated transcription factors in inflammation, aging and age-related diseases. Exp Gerontol 35:521-532

28. Noyman I, Marikovsky M, Sasson S et al. (2002) Hyperglycemia reduces nitric oxide synthase and glycogen synthase activity in endothelial cells. Nitric Oxide 7:187-193 
29. Hoffmann A, Gloe T, Pohl U (2001) Hypoxia-induced upregulation of eNOS gene expression is redox-sensitive: a comparison between hypoxia and inhibitors of cell metabolism. J Cell Physiol 188:33-44

30. Salt IP, Morrow VA, Brandie FM, Connell JM, Petrie JR (2003) High glucose inhibits insulin-stimulated nitric oxide production without reducing endothelial nitric-oxide synthase Ser1177 phosphorylation in human aortic endothelial cells. J Biol Chem 278:18791-18797

31. Ho FM, Liu SH, Liau CS, Huang PJ, Shiah SG, Lin-Shiau SY (1999) Nitric oxide prevents apoptosis of human endothelial cells from high glucose exposure during early stage. J Cell Biochem 75:258-263

32. Gallis B, Corthals GL, Goodlett DR et al. (1999) Identification of flow-dependent endothelial nitric-oxide synthase phosphorylation sites by mass spectrometry and regulation of phosphorylation and nitric oxide production by the phosphatidylinositol 3-kinase inhibitor LY294002. J Biol Chem 274:30101-30108

33. McCabe TJ, Fulton D, Roman LJ, Sessa WC (2000) Enhanced electron flux and reduced calmodulin dissociation may explain "calcium-independent" eNOS activation by phosphorylation. J Biol Chem 275:6123-6128
34. Michell BJ, Griffiths JE, Mitchelhil KI et al. (1999) The Akt kinase signals directly to endothelial nitric oxide synthase. Curr Biol 9:845-848

35. Fulton D, Gratton JP, McCabe TJ et al. (1999) Regulation of endothelium-derived nitric oxide production by the protein kinase Akt. Nature 399:597-601

36. Zou MH, Hou XY, Shi CM, Nagata D, Walsh K, Cohen RA (2002) Modulation by peroxynitrite of Akt- and AMP-activated kinase-dependent Ser1179 phosphorylation of endothelial nitric oxide synthase. J Biol Chem 277:3255232557

37. Marletta MA (1994) Nitric oxide synthase: aspects concerning structure and catalysis. Cell 78:927-930

38. Pieper GM (1997) Acute amelioration of diabetic endothelial dysfunction with a derivative of the nitric oxide synthase cofactor, tetrahydrobiopterin. J Cardiovasc Pharmacol 29:8-15

39. Hink U, Li H, Mollnau H, Oelze M et al. (2001) Mechanisms underlying endothelial dysfunction in diabetes mellitus. Circ Res 88:E14-E22

40. Zou MH, Shi C, Cohen RA (2002) Oxidation of the zincthiolate complex and uncoupling of endothelial nitric oxide synthase by peroxynitrite. J Clin Invest 109:817-826 